\title{
Remote Plasma Cleaning and Radical Recombination Rates
}

\author{
Ronald Vane ${ }^{1}$ and Ewa Kosmowska ${ }^{1}$ \\ ${ }^{1}$ XEI Scientific, Redwood City, CA, USA
}

Remote plasma cleaning of SEMs relies on oxidation of hydrocarbons by oxygen radicals (oxygen atoms $)\left({ }^{3} \mathrm{P}\right)$ generated by the plasma. These ground state atoms do not decay like metastables but are lost by chemical reactions either recombination or oxidation of other species. Oxidation of hydrocarbons to volatile molecules that can be pumped away is the basis of chemical etch, plasma cleaning. Quantum chemistry rules regarding energy loss state that these oxygen atoms do not react with diatomic molecules in two body collisions but require a third body to carry away excess energy kinetically. They also react on solid surfaces such as metals where they can react or recombine. Thus in the SEM vacuum chambers they are lost on chamber walls at pressure dependent recombination rates.

The concentration of neutral radicals in the plasma flowing afterglow is a function of the production rate in the plasma and the loss rate in the neutral afterglow. The production rate ( $\mathrm{Rp})$ is a function of the partial pressure of $\mathrm{O}_{2}\left(\mathrm{P}_{\mathrm{O} 2}\right)$, total pressure $\mathrm{P}$, power $\mathrm{W}$, device constants $\mathrm{D}$, and reaction rate constants $\mathrm{k}$. $\mathrm{Rp}=F\left(\mathrm{P}_{\mathrm{O} 2}, \mathrm{P}, \mathrm{W}, \mathrm{D}, \mathrm{k}\right)$. In this experiment, pressure was changed by changing the pump speed. The number radicals produced can be assumed to be the same at all pressures. The loss rate $\mathrm{R}_{\mathrm{L}}$ is a function of recombination rate by collisions (Rc) in the gas phase plus the loss rate due to collisions on the wall $(\mathrm{Rw}) . \mathrm{Rc}$ is a function of the three body collision rate which follows the total pressure cubed plus the loss rate to the wall $(\mathrm{Rw})$, which follows the total pressure and ratio of wall to volume of the plasma. Since the $\mathrm{Rc}$ is the most sensitive to pressure in an afterglow $\mathrm{P}_{\mathrm{O} 2} / \mathrm{P}$ will increase as the pressure is lowered until a crossover point is reached when the Rp drops below the $\mathrm{R}_{\mathrm{L}}$ and $\mathrm{Po}_{2}$ starts dropping with $\mathrm{P}$. The Rw is controllable by design of the location of the PRS on the vacuum chamber. The length and diameter of the radical conductance tube control the percentage of radicals that reach the chamber. The theory predicts that the shorter tube gives the better conductance and cleaning rates.

The commercial remote plasma cleaners available for SEMs generally attach the plasma radical source (PRS) for cleaning on an available port on the SEM chamber via KF40 or similar sized flanges, If an attempt is made to connect an extension pipe to move the Plasma Radical Source (PRS) further from the chamber because of other accessories and location of available ports, then radical concentration and cleaning rate is lost depending on the tube length.

To demonstrate the effect of distance and geometry on radical loss by recombination on tube walls, experiments were run using QCM (quartz crystal monitor) detectors to measure $\mathrm{O}$ radical concentration by measuring rate of removal of a hydrocarbon film. An Evactron ${ }^{\circledR} 25 \mathrm{Z}$ PRS was used at 20Watts RF power to produce $\mathrm{O}$ radicals. The length of the stainless steel radical delivery tube was varied from $9 \mathrm{~cm}$ to $32 \mathrm{~cm}$ between the Evactron ${ }^{\circledR}$ Zephyr ${ }^{\mathrm{TM}}$ PRS and the port on chamber wall. The input flow rate of air was set to $20 \mathrm{sccm}$. Previously reaction rates in chamber had been measured by QCMs at different distances within a chamber from the PRS port. In this experiment the QCMs were left in a fixed positions within the $20 \mathrm{~cm}$ diameter chamber and the PRS was moved away from the port by adding 40 mm diameter KF 40 nipples of different lengths between the port and the chamber. A turbo pump was used at two speeds to vary high vacuum pressure. At low vacuum pumping was done only by the roughing pump. Conductance varied the pressure at the QCM by small amounts. The experiment set ups are shown in Figures 1 and 2. The results for different lengths of tube are shown in Figure 3. 


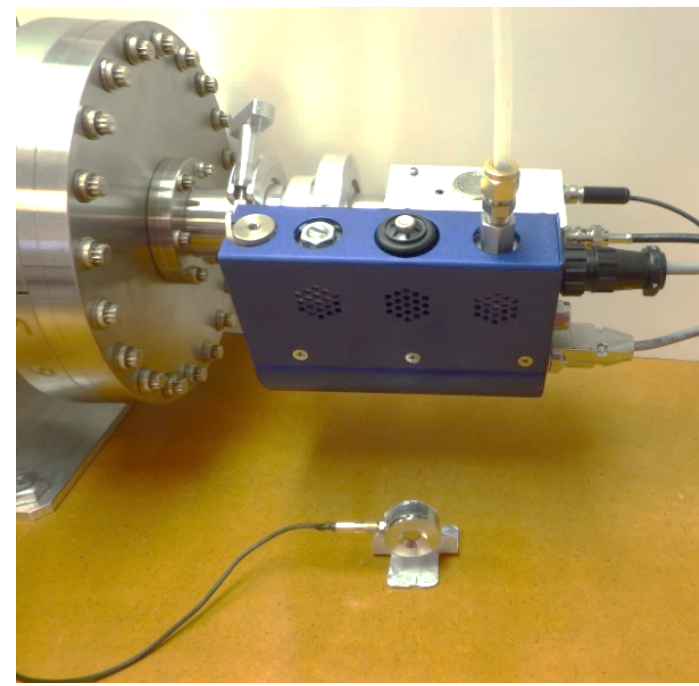

Figure 1. Evactron 25Z mounted $90 \mathrm{~mm}$ from the port wall. A QCM detector is exhibited on the table top.

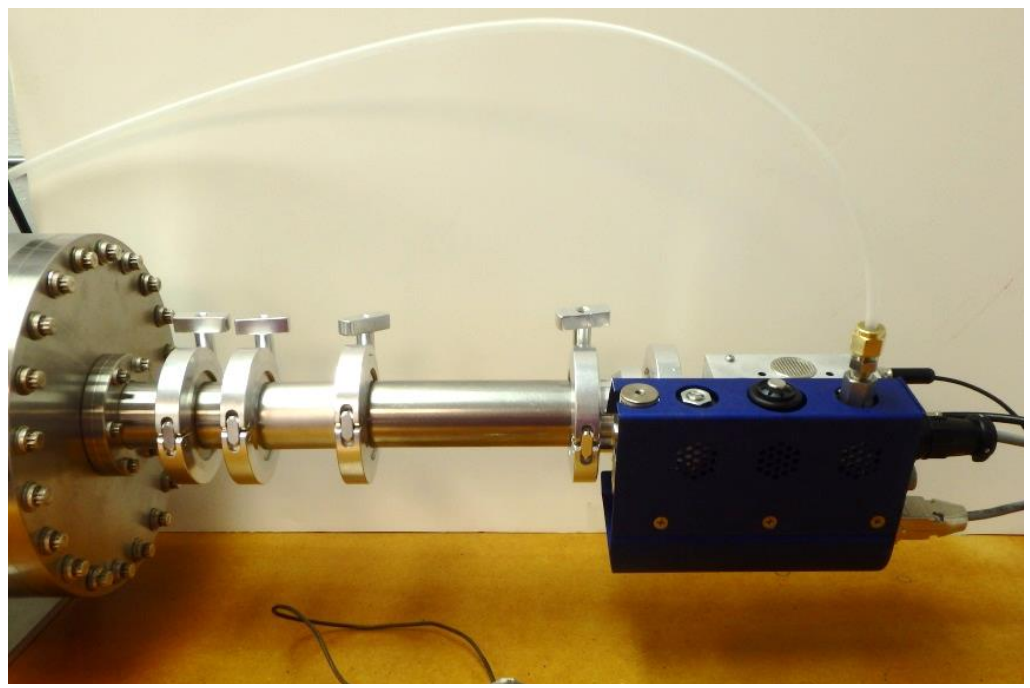

Figure 2. Evactron $25 \mathrm{Z}$ mounted $320 \mathrm{~mm}$ from the port wall.

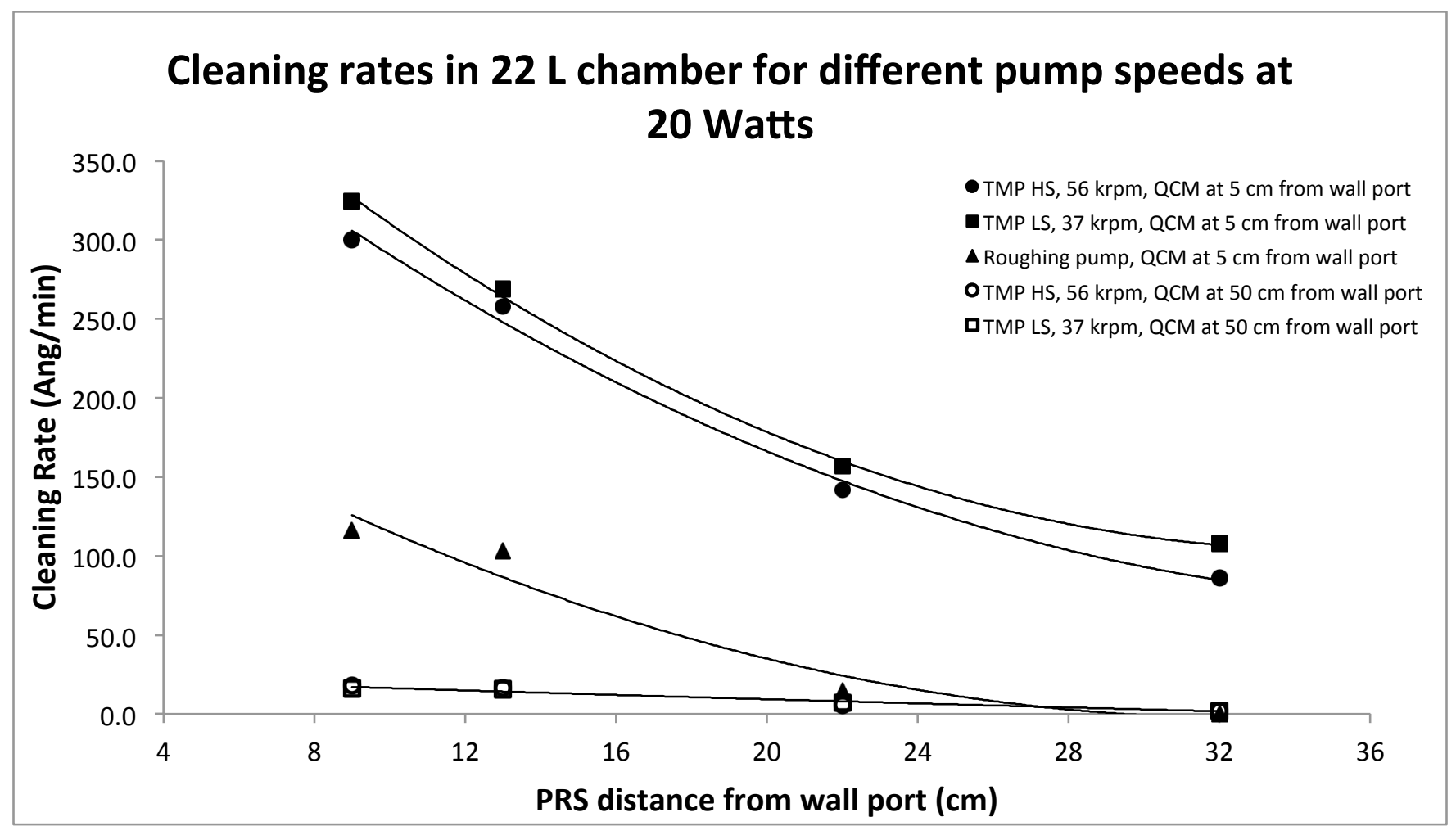

Figure 3. Cleaning rates measured for input air flow of $20 \mathrm{sccm}$. Pressure around electrode during plasma operation was measured to be: 14 mTorr with TMP at high speed, 19 mTorr with TMP at low speed and $220 \mathrm{mT}$ Torr with roughing pump on (rotary vane type). Cleaning rates at $50 \mathrm{~cm}$ from wall port with roughing pump were not detectable.

®Evactron is a registered trademark of XEI Scientific, Inc. 